\title{
The Gender Inequality in Chinese Textbooks
}

\begin{abstract}
Yuyue Jiang*
Wuxi Big Bridge Academy, Wuxi, Jiangsu, China

*Corresponding author. Email: guanghua.ren@gecacademy.cn

ABSTRACT

Gender stereotype is very common in daily life, and it will have a bad impact on immature children. In this review, this paper will discuss the manifestation of gender stereotypes and gender inequality in Chinese textbooks. Textbooks do not depict women and men objectively, and women are often portrayed as weak and dependent. However, men are often endowed with good qualities, such as ambition and courage. Textbooks have been irrigated gender inequality in children's minds unconsciously. Such descriptions will lead children to incorrect guidance and children will have obvious gender stereotypes in the future. It is effective and necessary to help children understand gender equality by changing gender stereotypes in textbooks. This study focuses on how gender stereotypes formed and some examples of gender inequality and stereotypes in Chinese textbooks. Moreover, this paper also expresses author's own opinions about changes in helping children become clearer about gender equality and stereotypes in the future.
\end{abstract}

Keywords: Gender Stereotypes, Gender Inequality, Chinese Textbooks

\section{INTRODUCTION}

Gender stereotypes appear in people's daily life. This is because gender stereotypes are created in their childhood under the influence of society and it is bad for people to have such opinions. Moreover, it is very difficult to change their opinions about gender equality when they grow up. It is defined as Beliefs about the supposed characteristics of men and women. It also refers to some generalized fixed views about gender [1]. Under the effect of gender stereotypes, people generalize some female/male characteristics and generalize them to the whole female/male group, while ignoring individual differences. For example, some people say that men are masculine, brave, rational, and confident; women are gentle and virtuous, ingenious; girls can't learn math well and boys can't learn languages well; men work outside, and women work inside; men are responsible for going out and women are responsible for housework and child-rearing. Gender stereotypes are largely sociocultural constructs. The socalled majority and minority refer to the relative majority and the relative minority in a particular cultural background. Therefore, in different cultural backgrounds, people's gender stereotypes also differ. Moreover, the paper also infers those different cultures can also lead to different kinds of gender stereotypes [2].

\section{HOW DOES GENDER STEREOTYPES FORM}

\subsection{Gender stereotypes from history}

Gender stereotypes start very early in history, and there was a time when women still had respect and status in society. Women can give birth to children, produce offspring for society, raise children and play important roles in the family [3]. And they could make tools to hunt for the men. They could bring food to the family and at that time, there wasn't a lot of prey, so the basic way of life was to rely on women. However, as the number of preys increased and people became more skilled at hunting, men could bring food to the family, and as families began to value men more, women began to lose their status. This is because men are physically stronger, so they can do more manual work to support the family. The woman became the caretaker of the children and husband at home. This is the history of the history. Moreover, children are guided to have gender stereotypes. Children received gender stereotypes from their daily life $[4,5]$. Therefore, the education of children may affect a lot to their future opinion of gender inequality and gender stereotypes. Gender stereotypes appear in people' $\mathrm{s}$ daily life. It is defined as Beliefs about the supposed characteristics of men and women. It also refers to some generalized fixed views 
about gender [1]. Under the effect of gender stereotypes, people generalize some female/male characteristics and generalize them to the whole female/male group, while ignoring individual differences. For example, some people say that men are masculine, brave, rational, and confident; women are gentle and virtuous, ingenious; girls can't learn math well and boys can't learn languages well; men work outside, and women work inside; men are responsible for going out and women are responsible for housework and child-rearing.

\subsection{Gender stereotypes from society}

Gender stereotypes are formed from society too. This is because men do the same to their wives based on the lifestyle of their predecessors, and over time they mistakenly conclude that they have more status and power than women although they may don't as good as women. Gradually, society may be influenced by the general trend and people are forming gender stereotypes from then on that women will never be as good as men simply because they are female, not male [6]. Men began to feel superior and that women were their means of procreation and nurturing and could be used to despise and vent at will [7]. Such opinions will also cause many scenes of gender inequality throughout female's life. For example, young boys are often more acceptable than a girl when they did something wrong because boys are thought to be naughty and heartless, but girls are often thought to be suspicious. Using one of my friends as an example, she once accidentally bumped into a classmate, the teacher asked her if there was a conflict between the two people, she was to retaliate by hitting others, but before that, a boy in her class also bumped into a classmate, the teacher just criticized him for running so fast. Girls are also thought to be good at art subjects and boys are good at science subjects. The image of men is mostly social, career, managerial and leisurely, while the life field of women is focused on the family. As a result, the occupations of men and women differ greatly, with men having a wide range of occupations, while women focus mainly on teachers, nurses, and waitresses. the occupations of men and women differ greatly, with men having a wide range of occupations, while women focus mainly on teachers, nurses, and waitresses [8]. This occupational division of labor also reflects the traditional gender stereotype that "men are in charge and women are in charge" [8]. Women are involved in 100 percent of household chores, while men are involved in 0 percent of household chores [8]. Even historically influential national leaders have been given domesticity. In addition, $91 \%$ of the men appeared to be tutoring their children, compared to $9 \%$ of the women. The content of men 's child counseling included parent-teacher conferences, teaching children not to use electrical appliances, and tutoring homework, while women 's child counseling consisted of teaching children not to use electrical appliances [8]. The content of men 's counseling included parent-teacher conferences, teaching children not to use electrical appliances, and tutoring homework, while women 's counseling consisted of teaching children not to use gas stoves, and teaching children to look at paintings and praise them [8]. When girls grow up, they may also meet some different questions such as office workers in large companies often ask women whether women have children, and they will be very glad if women have had children and they would not have more children [9]. This is because if they meet these requirements, they can work like men and do not need to take maternity leave. Moreover, many men wanted their wives to be housewives thus wives can take good care of husbands and children; however, then many men think that their wives are lack attention and then go outside to find other beautiful women.

\subsection{Gender stereotypes from education}

Gender stereotypes also spread a lot through education when children are young. When children stay with their parents, they can observe the interaction between father and mother. They can also have initial judgments that which of his parents is stronger and is responsible for big events in their families. Thus, they may also imitate the role of their parents and develop similar interactions with their partners in the future [10].

\subsubsection{Gender roles}

Gender role refers to the social behavior pattern that the society assigns to people according to their biological sex. The formation of a person's gender role is developed through socialization process on the basis of biological gender. In this process, people's basic biological characteristics, social experience acquired in life and their own cognitive development interact with each other and jointly affect the socialization of gender roles. The development of gender role is an important part of children's socialization, so it has always been a concern of developmental psychologists. In the research on gender role formation and development, it has been emphasized that preschool is an important stage of children's gender role formation. The psychoanalytic school, for example, stresses the critical period before the age of five. Psychologist Kohlberg also believes that the formation of children's gender roles between the age of 2 and 7 goes through three stages: The first one is gender identification which means children begin to understand whether they are girls or boys, and also know the gender of others; the second one is gender stability which means children recognize that a person's gender will not change, such as knowing that they are now a boy, and when they grow up, they cannot be a mother, can only be a man; which means gender 
consistency, children on the one hand recognize [11]. Gender can't be changed casually; however, they are willing to accept their gender and behave in accordance with their gender [11]. But as more research has been done on the subject, there is now a tendency to think that the critical age range for attaining male and female roles has widened, at least into adulthood and even throughout life [11]. Thus, we can say that the development of gender roles is still under way after a child enters school, and the social experience he gains in life is crucial for him. The teaching material becomes one of the ways for children to obtain social experience and the gender culture implied in the teaching material becomes the catalyst for the formation and development of children's gender roles [11].

\subsubsection{Negative impacts}

First of all, gender inequality in textbooks has a bad influence on the formation of students' gender consciousness. Gender consciousness is a concept and method to observe and understand many social phenomena and realize gender equality from the perspective of gender. Gender stereotypes allow students to naturally associate some behavioral traits with some people and extend them to other qualities that should not simply be attributed to gender, such as courage versus cowardice, intelligence versus stupidity [10]. This underpins existing gender inequalities. Such a result is not only not conducive to social progress, but also for the potential development of students in all aspects of physical and mental development and overall development [10]. Secondly, gender inequality in textbooks sets negative examples of gender roles for students [10]. In addition, it can be seen from the above analysis that there is gender bias in the proportion of male and female roles, overall image and ability, personality and other aspects in textbooks, and women are generally inferior to men [10]. Thirdly, gender inequality in teaching materials can easily lead to gender role conflicts among students, making it difficult for them to adapt to social life. This negative effect appears on both male and female students. Female students, the whole social and cultural environment, in the teaching materials constituted by the gender of female students living environment pressure, is not a good influence.[10]

\section{GENDER STEREOTYPES IN CHINESE TEXTBOOKS}

There are many gender stereotypes in Chinese textbooks. For example, women are often acted like wives who always listen to their husbands at home [9]. They won't be against their husbands' words. Moreover, they can also be teachers such as Arts teachers, Chinese teachers, and English teachers this is because women are thought to be not good at subjects who are logical such as math. However, men play a really important role such as brave policemen who are always willing to help people, and soldiers who are ready to dedicate their lives to their country. Little girls in the articles play the role of being weak and timid [10]. In contrast, boys are braver, more capable of problem-solving, more logical, and more intelligent. Children can shape a basic acknowledgment of the status of women and men when they are young from textbooks [11].

\subsection{Gender stereotypes in pictures}

Little children prefer looking at pictures instead of looking at words [12]. However, there are many pictures of gender stereotypes and inequality in Chinese textbooks in grades 1 to 4 . there are a lot of pictures of women who serve as housewives, and they always walk around the kitchen. They also often do everything for their husbands such as washing clothes and preparing meals for husbands. They also take good care of their children. Moreover, wives also always listen to their husbands no matter what husbands say. Maybe they are good wives, however, they lose the qualification of deciding their own life potentially. Men are often painted as people with decent jobs such as strong policemen or lawyers with the gift of gab. They seem extremely perfect both inside and outside. Thus, there appear gender stereotypes in the pictures of Chinese textbooks.

\subsection{Gender stereotypes in words}

As children get older, they become more receptive and more inclined to read with words [13]. For example, one Chinese author, Lu Xun, the article of him describes a vitriolic and his woman's furniture, however, he described the other as a man shun his furniture, described his very poor and helpless, totally different from the description of the woman before. So it's kind of scary that even one of China's most famous writers would have a sexual stereotype and spread it across the country. Thus, it is also the problem of gender stereotypes. Moreover, in the primary school "Society" course textbook (people's Education Press 1994 1998 edition), although the number of women is similar with that of men, there is a significant gap between men and women with independent identity, with $95 \%$ of men and $5 \%$ of women [14]. There are 17 texts titled with male characters' names in the 1-6 catalog of primary school "Society" course, and 28 male characters appear in the title of the course, while there is no female name in the whole catalog [14]. Similarly, in 2000, in the textbook, "Mathematics" for primary schools published by Beijing Normal University, the concept of the new curriculum reform was permeated in the textbook with pictures and pictures, but the editor also ignored gender [14]. The illustrations appeared more frequently in men than in women (1,023 for men and 542 for women) [13] 
Therefore, people interacted with gender stereotypes much more than they thought. Moreover, children like to discover and accept new things in the world, so people need to make some changes to Chinese textbooks. At least, men and women should be treated equally [14].

\section{CRITICISM OF GENDER STEREOTYPES IN TEXTBOOKS}

The paper discovers that there did exist many gender stereotypes and gender inequality in Chinese textbooks and people did find some reasons about how the gender stereotypes formed [14]. Our ordinary historiography has deliberately omitted anything about women or "femininity" to the extent that it remains difficult to believe that there were any women who played a significant role in history, or that anything as superficial as women and feminine values could have been a central force and played a role in the course of history. The fact is that women have played a role in the development of history. For example, history textbooks in China describe the only female emperor in the history of China as simply: Empress Wu Zetian abolished Zhongzong and established herself, renaming the country Zhou [8]. This was the only female emperor in the history of China [8]. She reigned for 22 years, and her so-called politics was nothing but brutal secret service rule [8]. Another scandalous act of Empress Wu was the indulgence of male attendants, which tainted politics [8].

Many teachers themselves also have serious problems with gender stereotypes and gender inequality [14]. In compulsory education textbooks, women are often described as supporters, even in the process of subject learning, where men are the central force in the activities and learning, and women are only supporters in the learning process [14]. The gender stereotypes in the textbooks are also reflected in the fact that boys are often portrayed with short hair, sports clothes, and actions related to intelligence, while girls are portrayed with pigtails, skirts, and actions related to housewife, good behavior, and timidity [14]. Moreover, they all embody the traditional women 's kindness, gentleness, patience, easygoing, diligence and so on; Men are great, high fashion, modest, open-minded, resolute, stubborn, ambitious, wise and brave, and so on [14]. On the contrary, women are stingy, ignorant, naive, malicious; Men are proud, cunning, mechanical, subjective and so on. In conclusion, all the males in the textbooks show the characteristics of male subjectivity and intelligence, while the females are more prominent in their primordiousness ability [14]. As a result, a grade two student wrote in a composition entitled "I see women in teaching materials": in teaching materials, people do not see wise mothers, in addition to working women, is a housewife. As if housework is the mother's only job, so in terms of life, I feel that only mother can be worthy of this responsibility, and in terms of career, it seems powerless [14]. In addition, male generic language is often used in textbooks. Textbooks full of gender-biased language will distort students' cognition of facts. For example, "Mothers get up early to clean, while fathers get up early to read books and newspapers" once appeared in textbooks, which strengthens mothers' duty to put housework first. "He's a doctor; She is a nurse "description and illustration, but also gender discrimination of occupation [14].

\section{CONCLUSION}

The paper reviews the phenomenon of gender stereotypes and the ways of solving the social phenomenon based on major fourteen educational society journals. In summary, the paper shows that: 1) How does gender stereotypes form; 2) Gender stereotypes from education; 3) Gender stereotypes from Chinese textbooks. These finding could be good references for those who plan to contribute to education and gender inequality. In addition, the results of our analysis would be helpful to decision makers in order to support their educational development.

\section{REFERENCES}

[1] David. Gender inequality in education: A case study of Eritrea.

[2] Margaret. Mead. (1988). Sex and temperament in three primitive tribes. Zhejiang People's Publishing House.

[3] Wang Shuai. The beginning of the Mother's Rights Myth. (Dissertation, East China University of Political Science and Law.

[4] Liu Xuan. The Structure and development of Gender Stereotypes in Adolescent Children. (Dissertation, Central China Normal University).

[5] Du Dan, \& Su Yanjie. (2005). The Influence of gender stereotype and stereotype information on children's toy choice. Psychological exploration,025(004), 56-61.

[6] Pan Teng, Sun Qingkuo, \& Hu Qizhou. (2018). Gender Inequality in Junior Middle School Mathematics textbooks. Journal of Jiangxi Institute of Education, 039(003), 4-8.

[7] Editorial Department, \& Yu Jing. (2011). Who has the final say in childbirth. Marriage and Family (Social Documentary) (02), 8-13.

[8] Yu Wei, \& Hu Jiao. (2005). Gender Inequality in China's Compulsory Education. Journal of Northeast Normal University. 
[9] Liu Meng, Wang Zhonghui, \& Dong Ou. (2004). Gender Discrimination in China's Employment Market: A Study on public Awareness rate. Journal of China Women's University, 16(006), 1-7.

[10] Zheng Ying, \& Lu Fangping. (2006). Gender Inequality in Chinese Primary and secondary school textbooks from the perspective of Educational Sociology. Journal of Sociology (2), 41-46.

[11] Jing Jianhua. (2006). The Rational Appeal of Gender equality in Education and the Realistic confusion of Gender Inequality in Primary and secondary school textbooks -- Also on the Influence of Children's gender role formation. Journal of Henan Institute of Education (Philosophy and Social Sciences) (06), 43-47.

[12] Liu Nina, Yan Guoli, \& Ding Min. (2012). Children's attention to characters in picture book reading before different reading styles. Preschool Education Research, 000(005), 10-16.

[13] Sun Qingkuo. (2019). Analysis and research on gender inequality in textbooks -- A case study of the Middle school mathematics textbooks of The Humanities Edition and Beijing Normal University edition. Journal of Teaching and Research, 2000 (004), 58-63.

[14] Hao Qiang Yang. Research on reproduction of Gender Inequality in Curriculum. (Dissertation, Southwest University). 